\section{Flu researchers slam US agency for hoarding data}

Influenza researchers are complaining that the poor sharing of data by the US disease-control agency is hindering their work.

Still reeling from accusations that his administration was unprepared for the hurricane that hit New Orleans last month, President George W. Bush called last week for an international partnership on influenza that would require countries facing an outbreak to share immediately information and samples with the World Health Organization (WHO).

But investigations by Nature have revealed widespread concern that too few of the flu data collected by the US Centers for Disease Control and Prevention (CDC) in Atlanta are made generally available. Experts say research would speed up if the CDC's influenza branch threw open its databases of virus sequences and immunological and epidemiological data.

"Many in the influenza field are displeased with the CDC's practice of refusing to deposit sequences of most of the strains that they sequence," says Michael Deem, a physicist at Rice University in Houston, who works on predicting flu vaccine efficiency.

Policy decisions, such as which vaccine to produce ahead of each flu season, are being made without the full data being available to the scientific community, he says. "The quality of their decisions, which can affect millions of people, cannot be checked."

Deem's criticisms are echoed widely, although most scientists are reluctant to speak on the record. "This is a very delicate issue. It is important to keep a positive working relationship with the CDC, and they do lots of things well," says one evolutionary ecologist. "But getting data from them has been somewhere between extremely difficult and impossible."

Researchers say they have no idea what or even how many flu sequences the CDC processes, but it is thought to be up to thousands each year. Apart from occasional large deposits accompanying published papers, required by journals, data are "coming through an eye dropper", says one bioinformatician at the US National Institutes of Health (NIH) in Bethesda, Maryland.

Nature's analyses show that, of about 15,000 influenza A sequences in the gene database
Genbank and the influenza sequence database at the Los Alamos National Laboratory in New Mexico, fewer than a tenth were deposited by the CDC. A consortium led by the US National Institute of Allergy and Infectious Diseases (NIAID) in Bethesda has deposited more than 2,800 sequences this year alone. "The advancement of public health and science is generally best served when data are shared in an open, timely and appropriate manner, and the CDC Influenza Branch is committed to accomplishing this objective," says James LeDuc, director of the CDC's division of viral and rickettsial diseases. But he adds: "This must be balanced against the needs for maintaining high standards for data quality and for protecting sensitive information when the situation warrants."

LeDuc says that as well as depositing sequences alongside papers, the agency posts summaries of epidemiological data on its website each week, and shares information with the WHO. But " we do not have the capacity to comply with all requests while also meeting

\section{CHICAGO}

Further evidence has emerged that money from the pharmaceuticalindustry is distorting the medicalliterature.

Meta-analyses - studies that combine the results from several trials - report more favourable results if they are sponsored by industry. The same effect had already been seen for clinical trials in several areas of medicine. But the new finding is even more worrying, say its authors, as policy-makers often give meta-analyses more weight than individual trials.

The latest result comes from a study of 71 meta-analyses of hypertension medications published between 1996 and 2002. The data in the industry-sponsored analyses were no more or less positive than those in publicly funded ones. But $93 \%$ of the meta-analyses funded by a single drug company drew positive conclusions about the medications

\section{IMAGE UNAVAILABLE FOR COPYRIGHT REASONS}

\author{
Shot in the dark: a lack of data \\ sharing could hold back the design \\ and assessment of flu vaccines.
}

our other public-health responsibilities".

Many flu scientists say that the CDC should try harder. "No other US laboratory receives thousands of influenza samples and sequences from around the globe," points out one. ${ }^{\alpha}$ They

\title{
Industry money skews drug overviews
}

- compared with $79 \%$ of those from academic institutions.

Many of the industry-funded papers reached conclusions not justified by the data, says study author Veronica Yank, an expert on medical publishing at the University of Washington in Seattle. She estimates that little more than half of the industry-funded studies that reached a favourable verdict actually had the data to back it up.

"Condusions in meta-analyses often spin the results to put them in a favourable light," says Yank, who presented her results on 17 September at the Fifth International Congress on Peer Review and Biomedical Publication in Chicago, Illinois. And, she notes, "meta-analyses often surpass clinical trials in terms on influence on policy".

"It's a marvellous study and very disturbing," says Richard Smith, chief 


\section{IMAGE \\ UNAVAILABLE FOR COPYRIGHT REASONS}

say it's in [their weekly report]," says another. "Give me a break. I want the database."

The dearth of CDC data was one reason why the NIAID last year created its consortium to sequence thousands of flu strains from

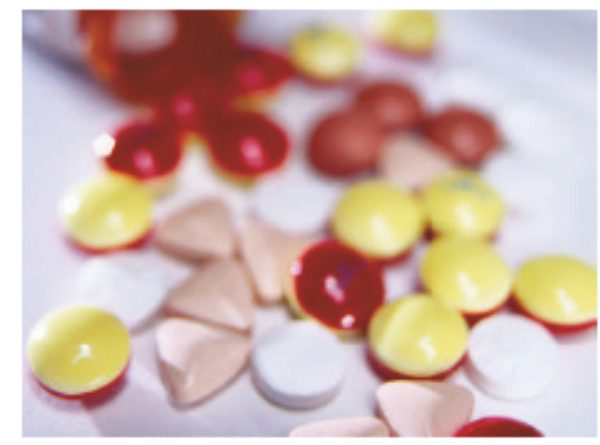

Bitter pill? Meta-analyses funded by drug companies are more likely to be positive.

executive of the London-based healthcare company UnitedHealth Europe and a former editor of the British Medical Journal (BM)).

The results should alert journal staff and reviewers, admit editors. They point out that referees should pick up conclusions that go beyond the data. "This is a massive failure of peer review," says Jeremy Theobald, an editor with the publishers humans and birds, according to one scientist close to the project. In one of the team's first papers, published in July (E. C. Holmes et al. PLaS Biology 3, e300; 2005), researchers found that viruses swap genes with each other much more frequently than was thought.

One such swap made the virulent Fujian strain, which hit in 2003-04, and to which the annual vaccine was poorly adapted. ${ }^{\alpha}$ The minute we got our hands on some open data, it jumped out that here was something people were not aware of," says one NIH scientist. "The CDC didn't know what was going on with the Fujian thing, and by the time they realized, it was too late to use it for a vaccine."

The threat of a flu pandemic makes it "imperative that our most experienced and brilliant scientists across the globe come together as one team, says Jill Taylor, a clinical virologist at the Wadsworth Center of the New York state department of health, and a member of the NIAID consortium.

“Open data are better," agrees William Glezen, a virologist at Baylor College of Medi-

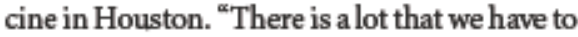
learn about influenza." A key issue, he says, is to match changes in the flu genome with the epidemiology of infections.

He acknowledges that CDC staff are busy with programmes such as the annual vaccine selection, and lack time and resources to share data better. "That's why other investigators need to look at the other parts," says Glezen. Declan Butler

John Wiley in Chichester, UK. Yank agrees: "I was embarrassed on behalf of the editors."

Yank did not say where the meta-analyses were published. Some editors say that smaller journals, which lack both the staff to scrutinize referees' reports and a large pool of submissions to choose, are more likely to accept flawed studies. Cathy DeAngelis, editor of the Journal of the American Medical Society (JAMA), says she is wary of industry-sponsored papers and always checks for bias, but questions whether all journals have the resources to do so.

Educating editors could tackle the problem, she suggests. Before the conference, JAMA paid for 20 editors from small journals, and some based in developing countries, to attend workshops on best practice in peer review.

Yank adds that journals can help by asking authors to place claims in the context of their data, and requiring them to own up to the limitations of the study.

Jim Giles 